\section{Replication-independent core histone dynamics at transcriptionally active loci in vivo}

\author{
Christophe Thiriet and Jeffrey J. Hayes ${ }^{1}$
}

Department of Biochemistry and Biophysics, University of Rochester Medical Center, Rochester, New York 14642, USA

We used a novel labeling technique in the naturally synchronous organism Physarum polycephalum to examine the fate of core histones in G2 phase. We find rapid exchange of $\mathrm{H} 2 \mathrm{~A} / \mathrm{H} 2 \mathrm{~B}$ dimers with free pools that is greatly diminished by treatment of the cells with $\alpha$-amanitin. This exchange is enhanced in pol II-coding sequences compared with extragenic regions or inactive loci. In contrast, H3/H4 tetramers exhibit far lower levels of exchange in the pol II-transcribed genes tested, suggesting that tetramer exchange occurs via a distinct mechanism. However, we find that transcribed regions of the ribosomal RNA gene loci exhibit rapid exchange of H3/H4 tetramers. Thus, our data show that the majority of the pol II transcription-dependent histone exchange is due to elongation in vivo rather than promoter remodeling or other pol II-dependent alterations in promoter structure and, in contrast to pol I, pol II transcription through nucleosomes in vivo causes facile exchange of both $\mathrm{H} 2 \mathrm{~A} / \mathrm{H} 2 \mathrm{~B}$ dimers while allowing conservation of epigenetic "marks" and other post-translational modifications on $\mathrm{H} 3$ and $\mathrm{H} 4$.

Supplemental material is available at http://www.genesdev.org.

Received September 23, 2004; revised version accepted January 27, 2005.

It has been known for several decades that activation of transcription by RNA polymerase II is accompanied by modulations in promoter chromatin structure, resulting in drastic increases in accessibility to endonucleases (Wu et al. 1979; Wu 1980; Keene et al. 1981). Multiple processes contribute to generating the open state of promoter regions, including disruption of canonical nucleosomes and higher order chromatin structures upon specific post-translational modifications of core histones (Roth et al. 2001; Zhang and Reinberg 2001) and the action of ATP-dependent chromatin remodeling complexes (Narlikar et al. 2002; Lusser and Kadonaga 2003). These processes likely work in concert at many loci (Cosma 2002; Boeger et al. 2003; Reinke and Horz 2003).

In addition to the structural alterations in chromatin associated with transcription initiation, some disruption

[Keywords: Chromatin; chromatin assembly; histone exchange; histones] ${ }^{1}$ Corresponding author.

E-MAIL jihs@mail.rochester.edu; FAX (585) 271-2683.

Article and publication are at http://www.genesdev.org/cgi/doi/10.1101/ gad.1265205. of nucleosome structure likely accompanies RNA pol II elongation in vivo. Early in vitro experiments suggested that $\mathrm{H} 2 \mathrm{~A} / \mathrm{H} 2 \mathrm{~B}$ dimers can be displaced by RNA polymerase II binding to nucleosome core particles (Baer and Rhodes 1983). Likewise, pulse-chase experiments in cultured mammalian cells indicated that exchange of $\mathrm{H} 2 \mathrm{~A} /$ H2B dimers in chromatin with newly synthesized histone pools occurs in a replication-independent (RI) fashion, while relatively little turnover of $\mathrm{H} 3 / \mathrm{H} 4$ tetramers was detected outside of S phase (Jackson and Chalkley 1985). Interestingly, RI incorporation of nascent H2A/ $\mathrm{H} 2 \mathrm{~B}$ occurs preferentially in nucleosomes containing acetylated H4 (Perry et al. 1993) and appears to be localized to transcriptionally active chromosomal regions (Hendzel and Davie 1990). Indeed, cytological analyses of GFP-histone fusions indicates that transcription-dependent exchange of $\mathrm{H} 2 \mathrm{~A} / \mathrm{H} 2 \mathrm{~B}$, but not $\mathrm{H} 3 / \mathrm{H} 4$, occurs in mammalian cells (Kimura and Cook 2001). However, Henikoff and collegues have shown that the histone variant $\mathrm{H} 3.3$ accumulates in a RI manner on rDNA repeats in Drosophila cells and quantification of H3.3 in nuclei of a Drosophila cell line suggests that exchange is widespread and includes many, if not all pol II-transcribed genes (Ahmad and Henikoff 2002; McKittrick et al. 2004).

A possible mechanism for the observed RI incorporation of $\mathrm{H} 2 \mathrm{~A} / \mathrm{H} 2 \mathrm{~B}$ was suggested by Studitsky and collaborators, who found that transcription of RNA pol II (but not RNA pol III or SP6 polymerase) through single nucleosomes in vitro led to the generation of histone hexamer-DNA complexes composed of a tetramer of $\mathrm{H} 3 / \mathrm{H} 4$ and a single $\mathrm{H} 2 \mathrm{~A} / \mathrm{H} 2 \mathrm{~B}$ dimer (Kireeva et al. 2002). Moreover, FACT, a complex that facilitates transcription elongation through nucleosomal templates by RNA pol II (Orphanides et al. 1999) and colocalizes on Drosophila polytene chromosomes with RNA pol II (Saunders et al. 2003), stimulates Pol II-dependent formation of hexamer-DNA complexes in vitro (Belotserkovskaya et al. 2003). However, while there is biochemical evidence supporting the hypothesis that RNA pol II activity induces exchange of $\mathrm{H} 2 \mathrm{~A} / \mathrm{H} 2 \mathrm{~B}$ dimers from chromatin, it is unclear whether the majority of exchange occurs during transcription initiation or elongation in vivo and whether pol II induces comparative levels exchange of $\mathrm{H} 3 / \mathrm{H} 4$ tetramers.

\section{Results and Discussion}

To investigate RI histone octamer dynamics in vivo, we used a novel labeling approach that exploits two remarkable properties of the slime mold Physarum polycephalum, its ability to grow as a single macropolasmodial cell with $\sim 10^{8}$ nuclei that proceed with complete synchrony through a 9-h cell cycle, and its ability to internalize exogenous proteins and complexes (Bradbury et al. 1974; Prior et al. 1980; Thiriet and Hayes 2001). While the majority of histone synthesis in Physarum occurs during $S$ phase, when replication of chromatin takes place, extrachromosomal elements containing the rDNA loci are known to replicate throughout the cell cycle (Benard et al. 1995), indicating that pools of histone remain available during G2 phase (note Physarum lacks a distinct $\mathrm{G} 1$ phase). In addition, some $\mathrm{H} 2 \mathrm{~A} / \mathrm{H} 2 \mathrm{~B}$ dimer synthesis is known to occur during G2 phase (Loidl and 
Grobner 1987). To study the fate of exogenous H2A/H2B dimers incorporated into Physarum cells during G2 phase, we prepared $\mathrm{H} 2 \mathrm{~A} /$ Flag-H2B dimers in which nine amino acid residues containing the Flag epitope were added to the $\mathrm{N}$ terminus of $\mathrm{H} 2 \mathrm{~B}$ (Thiriet 2004). The antiFlag antibody did not cross-react with any Physarum epitopes or hinder the ability of the Flag dimer to reconstitute into nucleosomes in vitro (Fig. 1B; Supplementary Fig. S2; data not shown). H2A/Flag-H2B dimers introduced into Physarum cells during G2 phase almost exclusively localized to nuclei (Fig. 1A,B). We estimated that the exogenous proteins represent $\leq 5 \%$ of the total $\mathrm{H} 2 \mathrm{~A} / \mathrm{H} 2 \mathrm{~B}$ in the cell (see Materials and Methods). Experiments carried out in the absence or presence of $\alpha$-amanitin, which inhibits RNA polymerase II transcription in a wide range of organisms including Physarum (Pierron and Sauer 1980; Bushnell et al. 2002), showed that the nuclear localization of the exogenous $\mathrm{H} 2 \mathrm{~A} /$ Flag-H2B was independent of transcription (Fig. 1A,B).

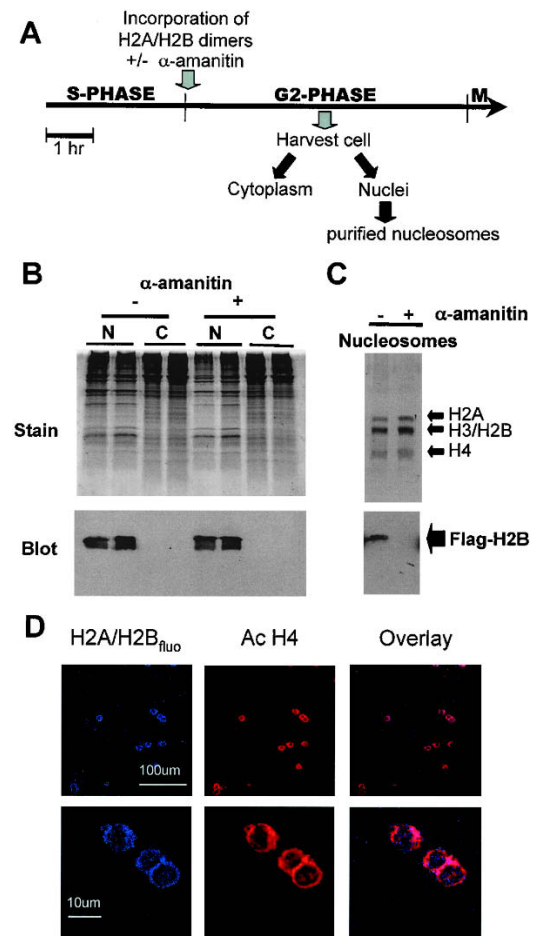

Figure 1. Exogenous core histones $\mathrm{H} 2 \mathrm{~A} / \mathrm{H} 2 \mathrm{~B}$ localize to Physarum nuclei and are assembled into nucleosomes when introduced during G2 phase. (A) Experimental strategy for incorporation of exogenous histones into Physarum cells. Solutions containing H2A/Flag-H2B were applied to the upper surface of macroplasmodia at the beginning of G2 phase, then cells were grown for $3 \mathrm{~h}$ prior to analysis. $(B)$ Exogenous $\mathrm{H} 2 \mathrm{~A} / \mathrm{H} 2 \mathrm{~B}$ localize to nuclei independent of transcription. Proteins were introduced at the beginning of G2 phase in the absence or presence of $\alpha$-amanitin and subcellular distribution in nuclear $(\mathrm{N})$ and cytoplasmic $(\mathrm{C})$ fractions analyzed by SDS-PAGE and Western blots with anti-Flag antibodies. Duplicate experiments are shown. $(C)$ Exogenous H2A/Flag-H2B is assembled into nucleosomes via an $\alpha$-amanitin sensitive process. Nucleosomes were purified from macroplasmodia treated with exogenous $\mathrm{H} 2 \mathrm{~A} / \mathrm{H} 2 \mathrm{~B}$ in the absence or presence of $\alpha$-amanitin and protein content analyzed. (Top) Coomassie-stained gel. (Bottom) Western blot of the gel. (D) Exogenous $\mathrm{H} 2 \mathrm{~A} / \mathrm{H} 2 \mathrm{~B}$ dimers colocalize with transcriptionally active chromatin. Incorporation of fluorescein-labeled dimers was carried out in G2 phase for $3 \mathrm{~h}$, cell explants were squashed, fixed, and stained for acetylated $\mathrm{H} 4$ with antipenta-acetylated $\mathrm{H} 4$ peptide antibodies. Nuclei were imaged by confocal microscopy.
We previously had found that $\mathrm{H} 2 \mathrm{~A} / \mathrm{H} 2 \mathrm{~B}$ localized within nuclei could remain unassembled into chromatin during $S$ phase, strongly suggesting the existence of a pool of free nuclear histones (Thiriet and Hayes 2001). Thus, the accumulation of $\mathrm{H} 2 \mathrm{~A} / \mathrm{H} 2 \mathrm{~B}$ dimers in $\mathrm{G} 2 \mathrm{nu}-$ clei did not necessarily indicate assembly into chromatin. Therefore, we examined whether the exogenous proteins were assembled into nucleosomes, and whether this incorporation was dependent upon RNA polymerase II activity. Nuclei were prepared from $\alpha$-amanitin treated and untreated plasmodia and mononucleosomes isolated by MNase digestion, followed by sucrose gradient fractionation. Western blots of proteins from the mononucleosome fractions clearly showed that Flag-tagged $\mathrm{H} 2 \mathrm{~A} / \mathrm{H} 2 \mathrm{~B}$ dimers were present in nucleosomes isolated from control cells not treated with $\alpha$-amanatin, but were greatly diminished in nucleosomes from cells treated with the drug (Fig. 1C). These results indicate that although exogenous H2A/H2B dimers localize into Physarum nuclei regardless of transcriptional activity, assembly of dimers into nucleosomes during G2 phase is dependent upon transcription by RNA polymerase II.

Numerous studies have shown that histone acetylation is correlated with RNA polymerase II activity. Therefore, to substantiate the above observations, we compared the intranuclear localization of histone $\mathrm{H} 4$ acetylation, previously shown to colocalize with transcriptional activity in Physarum nuclei (Waterborg and Matthews 1983) and exogenous H2A/H2B modified with fluorescein. Confocal analyses of squashes stained with antibodies to acetylated $\mathrm{H} 4$ and direct fluorescence showed that labeled dimers colocalized in transcriptionally active regions located near the nuclear periphery (Fig. 1D; Waterborg and Matthews 1983). This pattern contrasted with exogenous $\mathrm{H} 2 \mathrm{~A} / \mathrm{H} 2 \mathrm{~B}$ dimers incorporated during $S$ phase, which stained chromatin homogeneously throughout the nucleus (Thiriet and Hayes 2001) and suggests a global relationship between transcription activity and incorporation of $\mathrm{H} 2 \mathrm{~A} / \mathrm{H} 2 \mathrm{~B}$ dimers into chromatin during G2 phase.

To exclude the possibility of indirect effects of $\alpha$-amanitin and further investigate the RI incorporation of $\mathrm{H} 2 \mathrm{~A} / \mathrm{H} 2 \mathrm{~B}$ into chromatin, we examined specific loci by chromatin immunoprecipitation (ChIP) analysis of macroplasmodia treated with $\mathrm{H} 2 \mathrm{~A} / \mathrm{Flag}-\mathrm{H} 2 \mathrm{~B}$ dimers. Two developmentally regulated Physarum profilin genes, one inactive and the other actively transcribed, (Fig. 2A) were chosen as targets for ChIP (Maric et al. 2003). Chromatin immunoprecipitations from cells prepared in the absence of exogenous dimers showed that neither of the targeted sequences bound nonspecifically to the antiFlag antibody-coated beads under our experimental conditions (Fig. 2B, lane 2). ChIP experiments with cells in which $\mathrm{H} 2 \mathrm{~A} /$ Flag-H2B dimers were incorporated during G2 phase indicated that the exogenous dimer was assembled into chromatin at the active ProP locus to a significantly greater extent than the silent ProA locus (Fig. 2B, lane 4). We noted some exogenous dimer was detectable at the silent locus, perhaps due to a lower level of DNA repair-related "background" incorporation of dimers (Mello and Almouzni 2001).

Differences in $\mathrm{H} 2 \mathrm{~A} / \mathrm{H} 2 \mathrm{~B}$ dimer exchange between the active and inactive profilin genes may be due to a greater locus-wide passive exchange of dimers, promoter remodeling, or the direct action of the elongating polymerase. In order to address this issue, we examined $\mathrm{H} 2 \mathrm{~A} / \mathrm{H} 2 \mathrm{~B}$ 


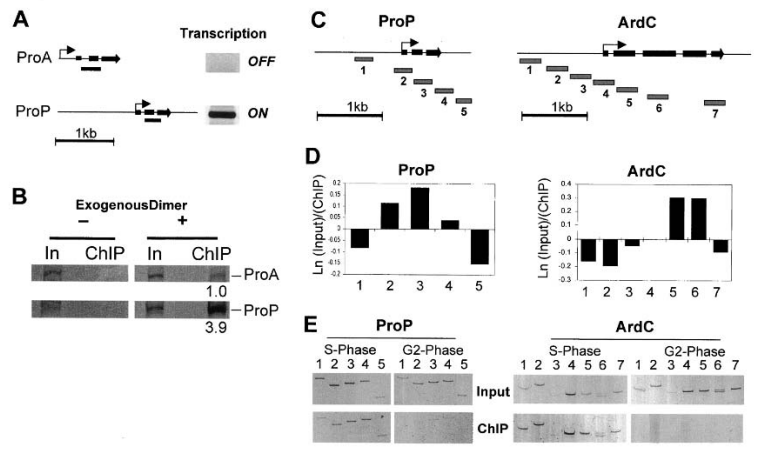

Figure 2. Exogenous $\mathrm{H} 2 \mathrm{~A} / \mathrm{H} 2 \mathrm{~B}$ dimers are preferentially assembled into nucleosomes on transcribed sequences of active genes. $(A)$ Diagram of profilin ProA and ProP loci, which are transcriptionally inactive and active, respectively, in Physarum macroplasmodia. Lines below the loci correspond to the fragments analyzed in $B$. (Right) The transcription state of the genes was confirmed by RTPCR. (B) Incorporation of exogenous H2A/H2B into Physarum chromatin. Extract from an untreated control cell $(-)$ or a single cell treated with exogenous $\mathrm{H} 2 \mathrm{~A} / \mathrm{H} 2 \mathrm{~B}(+)$ as described in Figure $1 \mathrm{~A}$ was analyzed by ChIP. The enrichment of fragments after the immunoprecipitation from the active ProP locus relative to the ProA locus is listed below the lanes (average of two experiments). PCR reaction products using the input extract (In) and the immunoprecipitate (ChIP) are shown. (C-E) Incorporation of exogenous histone complexes into Physarum chromatin throughout the ProP and ArdC loci. $(C)$ DNA regions amplified by PCR in the ChIP assays (bars below lines). (D) Extent of incorporation of exogenous H2A/Flag$\mathrm{H} 2 \mathrm{~B}$ into chromatin during G2 phase. Histones were introduced at the beginning of G2 phase, and cells harvested for ChIP $3 \mathrm{~h}$ later. Numbers correspond to individually amplified regions shown in $C$. The intensities of amplified bands were normalized to internal controls and the $\ln$ (ChIP band)/(input band) shown in the bar graph. $(E)$ Incorporation of exogenous $\mathrm{H} 3 / \mathrm{H} 4$ into chromatin throughout the ProP and ArdC loci during S and G2 phase. Exogenous $(\mathrm{H} 3 / \mathrm{H} 4)_{2}$ tetramers were introduced into Physarum cells at the beginning of S or G2 phase, and the extent of incorporation into chromatin throughout each locus was analyzed $3 \mathrm{~h}$ later as in $D$.

dimer exchange in extragenic versus coding regions of the active ProP locus and a second locus, ArdC, which includes a constitutively active actin gene (Fig. 2C). The quantification of ChIP results in the ProP locus reveals that the exchange of exogenous dimers into chromatin was low in the promoter region, increased in the coding region, and decreased at the end of the coding region (Fig. $2 \mathrm{C}, \mathrm{D}$, left). However, because of a poly A/T track in the ProP promoter region, we could not examine the extent of assembly in this region in greater detail. Analysis of the $\operatorname{ArdC}$ locus revealed the same general pattern as on the ProP locus, where the promoter region exhibited a lower exchange, while the coding region exhibited a higher level of assembly with a decrease at the end of the coding region (Fig. 2C,D, right). We therefore conclude that histone dimers exchange with a significantly higher efficiency within actively transcribed compared with extragenic sequences.

The above results show that RNA pol II transcription induces $\mathrm{H} 2 \mathrm{~A} / \mathrm{H} 2 \mathrm{~B}$ exchange with free pools and that this exchange is highly localized to transcribed sequences. We next determined whether incorporation into chromatin and differential exchange also occurs for the $\mathrm{H} 3 / \mathrm{H} 4$ tetramer. We first incorporated Flag-tagged $\mathrm{H} 3 / \mathrm{H} 4$ tetramers into macroplasmodia during $S$ phase to determine whether these proteins assembled into native
Physarum chromatin in vivo (Thiriet and Hayes 2001). The exogenous H3/H4 localized to Physarum nuclei and are assembled into nucleosomes (Supplementary Fig. S2), constituting $<5 \%$ of total endogenous $\mathrm{H} 3 / \mathrm{H} 4$ estimated as above for $\mathrm{H} 2 \mathrm{~A} / \mathrm{H} 2 \mathrm{~B}$ (data not shown). ChIP experiments with the same sequences examined for the H2A/ $\mathrm{H} 2 \mathrm{~B}$ experiments showed that when incorporated during $\mathrm{S}$ phase, exogenous $\mathrm{H} 3 / \mathrm{H} 4$ tetramers were associated with all sequences tested throughout the ProP and ArdC loci (Fig. 2E, S-Phase).

To examine the RI assembly of $\mathrm{H} 3 / \mathrm{H} 4$ into chromatin during G2 phase, exogenous proteins were incorporated at the onset of G2 phase under identical conditions to those used for $\mathrm{H} 2 \mathrm{~A} / \mathrm{H} 2 \mathrm{~B}$ and assembly into chromatin analyzed by the ChIP assay. The results of the PCR amplification revealed that the exogenous tetramers were not efficiently incorporated into chromatin at any position throughout these loci (Fig. 2E, G2-Phase). Note the extremely low incorporation of exogenous tetramers in G2 phase did not allow for accurate determination of relative amounts of incorporation across the locus. We estimate that the incorporation of the $\mathrm{H} 3 / \mathrm{H} 4$ in $\mathrm{G} 2$ phase to be at least 10 -fold lower than the incorporation in $S$ phase. These results are consistent with the examination of global incorporation of exogenous tetramer in G2 phase (data not shown). Therefore, we concluded that although the exogenous $\mathrm{H} 3 / \mathrm{H} 4$ tetramers were efficiently assembled into native chromatin in a replicationdependent manner during $S$ phase, in contrast to $\mathrm{H} 2 \mathrm{~A}$ / $\mathrm{H} 2 \mathrm{~B}$, these proteins did not exhibit appreciable transcription-dependent incorporation into chromatin during G2 phase.

The experiments above monitored the incorporation of Flag-tagged histones into chromatin at specific loci. However, it is possible that exchange during transcription, especially exchange of $\mathrm{H} 3 / \mathrm{H} 4$ tetramers, is limited to a specific histone variant, such as tetramers containing H3.3, since some major $\mathrm{H} 3 \mathrm{~s}$ appear to not contain critical sequences required for RI exchange (Ahmad and Henikoff 2002). Thus, to examine the possibility that pol II-dependent exchange requires protein sequences and or post-translational modifications not present within our exogenous proteins, and to determine the relative rate of exchange of core histones at specific loci, we incorporated trace amounts of exogenous Flag-tagged histones in $S$ phase, washed the cells, then monitored the replacement of the tagged histones at specific loci during G2 phase. Note that this procedure would detect exchange of any endogenous histones including RI-specific histone variants. Consistent with previous results, we found that only a very small fraction of the total $\mathrm{H} 2 \mathrm{~A} / \mathrm{H} 2 \mathrm{~B}$ dimer on the silent ProA locus underwent exchange with endogenous free histones during G2, while, in contrast, the active $A r d C$ locus exhibited a striking pattern of exchange with the free pool of endogenous histones. Moreover, exchange of $\mathrm{H} 2 \mathrm{~A} / \mathrm{H} 2 \mathrm{~B}$ was significantly more rapid for the coding region than the promoter region of the ArdC locus (Fig. 3).

In contrast, analyses of the kinetics of exchange of $\mathrm{H} 3 / \mathrm{H} 4$ tetramers during G2 phase revealed that the exogenous histone tetramers did not undergo significant exchange from chromatin in either active or inactive loci. Indeed, we found that maximally only $\sim 5 \%$ of the total $\mathrm{H} 3 / \mathrm{H} 4$ tetramers exchanged in transcribed regions, in contrast to $\sim 90 \%$ for $\mathrm{H} 2 \mathrm{~A} / \mathrm{H} 2 \mathrm{~B}$ dimers. Therefore, our data show that RNA Pol II elongation does not induce 
exchange of the vast majority of $\mathrm{H} 3 / \mathrm{H} 4$ tetramers on these genes, excluding the possibility that significant amounts of tetramer exchange was not detected in previous experiments due to a requirement for a specific histone variant.

We next considered the possibility that since transcription and replication overlap in the selected active loci, significant levels of a transcription-related histone variant may have been assembled during $S$ phase, perhaps to the exclusion of the exogenous proteins. In this case, little turnover of labeled proteins incorporated during $S$ phase might be detected. To address this possibility, we repeated the analysis on another locus that is known to be transcriptionally silent during $S$ phase, but is induced during G2 phase. The $\alpha$-tubulin B gene locus $(A 1 t B)$ is actively transcribed only at the end of G2 phase and replicates in early $S$ phase, with no overlap between the two processes (Carrino and Laffler 1986). We incorporated histones in S phase, washed the cells, and analyzed the histone content at the $A$ ltB locus before and after activation of the gene during G2 phase. Despite the small size of this locus, the extent and pattern of exchange is consistent with the other loci. We find little difference in the extent of exchange of $\mathrm{H} 3 / \mathrm{H} 4$ between cells harvested before or after transcription of the gene is initiated (Fig. 4, black bars). However, after $1 \mathrm{~h}$ of transcriptional activation, $\mathrm{H} 2 \mathrm{~A} / \mathrm{H} 2 \mathrm{~B}$ histone dimers exhibit low levels of exchange in extragenic regions and higher levels of exchange in the intragenic regions (Fig. 4, gray bars). In contrast, exchange of histone $\mathrm{H} 3 / \mathrm{H} 4$ tetramers

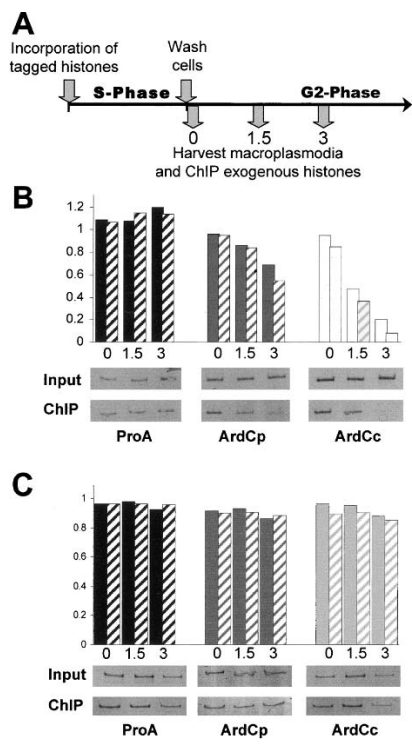

Figure 3. Kinetics of exchange of core histone proteins on active loci. $(A)$ Experimental strategy. Nucleosomes were labeled in vivo by incorporation of Flag-tagged histones at the beginning of $\mathrm{S}$ phase for $3 \mathrm{~h}$; the cells were then washed, and the loss of labeled proteins from the chromatin of the indicated loci monitored by ChIP immediately $(0)$ and 1.5 and $3 \mathrm{~h}$ after washing. $(B)$ Exchange of $\mathrm{H} 2 \mathrm{~A} / \mathrm{H} 2 \mathrm{~B}$ on sequences within the inactive ProA gene (ProA) and the active ArdC promoter (ArdCp) and coding region (ArdCc). Primers used were, ProA, ArdC 2, and ArdC 6 from Figure 2. The enrichment of the target sequence relative to the $0.5 \%$ of the input is plotted with results from two independent experiments shown. (C) Exchange of $\mathrm{H} 3 / \mathrm{H} 4$ was monitored as in $B$, except that cells were treated with H3/Flag-H4.

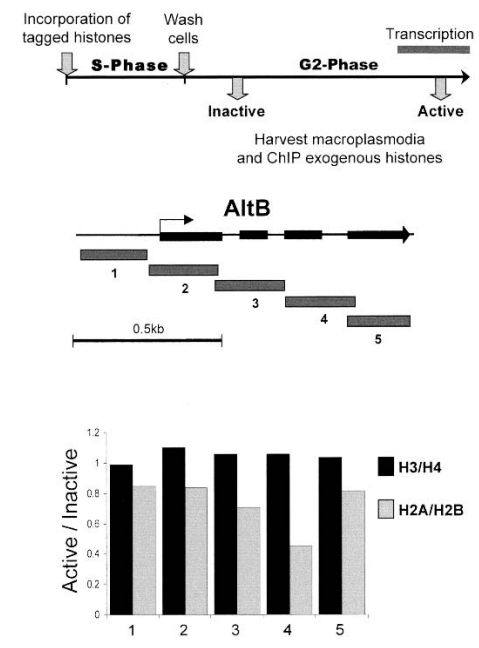

Figure 4. Exchange of core histone proteins throughout the AltB locus before and after activation of transcription. Core histones on endogenous sequences were labeled in vivo as in Figure 3; then, the relative amount of $\mathrm{H} 2 \mathrm{~A} / \mathrm{Flag}-\mathrm{H} 2 \mathrm{~B}$ and $\mathrm{H} 3 / \mathrm{Flag}-\mathrm{H} 4$ associated with each AltB sequence was determined before (Inactive) and after (Active) transcription activation of the gene. The ratio of Active/Inactive ChIP was plotted for each of the indicated sequences. Results are the average of two independent experiments with $\leq 5 \%$ average variation.

is minimal throughout the locus, regardless of when the ChIP experiment is carried out, consistent with the results obtained with the ProA and ArdC loci. These results indicate that accumulation of specialized transcription-related histone variants during $S$ phase did not affect our determination of histone turnover on these loci.

Our results indicate that little or no transcription-dependent exchange of $\mathrm{H} 3 / \mathrm{H} 4$ occurs on the active pol II loci examined. Since RI independent incorporation of H3.3-GFP/H4 has been observed on pol I-transcribed rDNA loci in Drosophila cells (Ahmad and Henikoff 2002), we examined whether exchange of H3/H4 occurs on Physarum rDNA loci using our "ChIP-decay" assay. Importantly, we found efficient exchange of $\mathrm{H} 3 / \mathrm{H} 4$ could be detected in pol I-transcribed regions compared with the nontranscribed ribosomal gene spacer elements (Supplementary Fig. S3). Importantly, both the spacer elements and the transcribed region appear to be assembled into nucleosomes to an extent similar to bulk chromatin (Supplementary Fig. S3). These data strongly suggest the presence of an H3.3-like activity in Physarum and are in agreement with results from other systems (Ahmad and Henikoff 2002; Malik and Henikoff 2003; see below).

Our results support a model whereby RNA polymerase II elongation through nucleosomes induces displacement of $\mathrm{H} 2 \mathrm{~A} / \mathrm{H} 2 \mathrm{~B}$ dimers followed by nucleosome reassembly in vivo. We find that $\mathrm{H} 2 \mathrm{~A} / \mathrm{H} 2 \mathrm{~B}$ are incorporated into nucleosomes in vivo in a replication-independent manner that requires the activity of RNA polymerase II, and that this exchange is confined to regions transcribed by the polymerase. Exchange of $\mathrm{H} 3 / \mathrm{H} 4$ occurs with a rate that is at least 20 times slower than exchange of $\mathrm{H} 2 \mathrm{~A} / \mathrm{H} 2 \mathrm{~B}$, and does not appear to be localized to transcribed regions in the pol II loci tested. This model is consistent with the observations that in a purified model system, RNA polymerase II elongation through nucleosomes in vitro generates a histone hexamer-DNA com- 
plex lacking a single $\mathrm{H} 2 \mathrm{~A} / \mathrm{H} 2 \mathrm{~B}$ dimer (Kireeva et al. 2002), and that the chromatin-specific transcription elongation complex FACT stimulates formation of hexamers in this system (Belotserkovskaya et al. 2003). These complexes are perhaps related to the partial nucleosomes previously observed after pol II transcription of chromatin templates in vivo (Sathyanarayana et al. 1999), and may represent intermediates during the facile exchange of histone dimers with free pools in vivo observed in our experiments. Importantly, our data indicate that both $\mathrm{H} 2 \mathrm{~A} / \mathrm{H} 2 \mathrm{~B}$ dimers are eventually displaced by passage of the polymerase. Finally, based on quantification of immunoreactivity and total proteins, we estimate the fraction of nucleosomes in which exogenous $\mathrm{H} 2 \mathrm{~A} / \mathrm{H} 2 \mathrm{~B}$ has been incorporated in an $\alpha$-amanatin-sensitive manner to be $\sim 1 \%$, suggesting that the exchange is widespread and involves many pol II genes.

Initiation of transcription involves the opening of chromatin structure at the promoter region to provide access for transcription factors to bind DNA sequences (Wolffe 1998). In most cases, promoter chromatin disruption involves histone post-translational modification and nucleosome remodeling, and recent analysis indicates that ATP-dependent chromatin remodeling complexes can catalyze the exchange of $\mathrm{H} 2 \mathrm{~A} / \mathrm{H} 2 \mathrm{~B}$ dimers between chromatin fragments in vitro (Bruno et al. 2003). However, our results indicate that the majority of $\mathrm{H} 2 \mathrm{~A} / \mathrm{H} 2 \mathrm{~B}$ exchange is confined to the structural gene itself; thus, promoter remodeling accounts for little of the overall exchange observed in previous in vivo experiments (Hendzel and Davie 1990; Kimura and Cook 2001). Importantly, our results demonstrate that this exchange is likely due to RNA polymerase II elongation through the chromatinized structural gene rather than just greater levels of passive exchange in transcriptionally active, highly acetylated, open chromatin domains. Nonetheless, it is possible that remodeling activities facilitate dimer exchange during elongation.

The far lower levels of RI exchange we and others (Kimura and Cook 2001) detect for H3/H4 compared with $\mathrm{H} 2 \mathrm{~A} / \mathrm{H} 2 \mathrm{~B}$ suggest that these two phenomena are not directly mechanistically linked in vivo. This is in contrast to replication during $\mathrm{S}$ phase, where both $\mathrm{H} 2 \mathrm{~A}$ / $\mathrm{H} 2 \mathrm{~B}$ dimers and $\mathrm{H} 3 / \mathrm{H} 4$ tetramers are incorporated into Physarum chromatin to approximately equal extents (Thiriet and Hayes 2001; Fig. S2). Thus, replacement of tetramers containing major H3 with H3.3 (Ahmad and Henikoff 2002) does not appear to occur to a significant extent on any of the polymerase II genes we investigated. While it is unclear whether Physarum contains a specialized H3.3-like variant, biochemical analyses indicate the presence of at least two independently synthesized $\mathrm{H} 3$ variants (J. Waterborg, pers. comm.). Nonetheless, it is important to note that in all organisms examined to date, H3.3-like RI exchange activity is supplied by either a specialized H3 variant or is inherent within a dualpurpose H3.3, as in yeast (Malik and Henikoff 2003). Thus, our data raise the possibility that pol II-dependent incorporation of $\mathrm{H} 3.3 / \mathrm{H} 4$ tetramers is a relatively infrequent process, such that significant accumulation occurs only on highly transcribed loci and/or that such an exchange is specific to pol I-transcribed regions (Ahmad and Henikoff 2002; Supplementary Fig. S3). Indeed, recent comparisons of the level of RNA polymerase II activity and the ability to ChIP histones $\mathrm{H} 3 / \mathrm{H} 4$ on specific sequences in yeast cells suggest that transient displace- ment of nucleosomes can occur on highly transcribed sequences in this organism (Lee et al. 2004; Schwabish and Struhl 2004). Finally, it will be interesting to examine whether processes such as nucleotide excision repair account for the "background" level of exchange we observed on silent loci (Mello and Almouzni 2001).

\section{Materials and methods}

\section{Physarum cultures}

Physarum polycephalum strain TU291 was maintained in liquid culture. Naturally synchronous macroplasmodia were cultured as described (Thiriet and Hayes 1999b) and remain completely synchronous through several 9-h cell cycles. The onset of mitosis was determined by phase contrast microscopy of tiny explants (Thiriet and Hayes 1999b). The 15 -min mitosis is directly followed by $3 \mathrm{~h}$ of $\mathrm{S}$ phase (determined by ${ }^{3} \mathrm{H}$ thymidine incorporation; data not shown), then a 6-h G2 phase. There is no G1 phase.

\section{Preparation of exogenous proteins and incorporation into} macroplasmodia

Flag-tagged histones $\mathrm{H} 2 \mathrm{~B}$ and $\mathrm{H} 4$ were generated by addition of the Flagcoding sequence to the wild-type Xenopus genes expressed in bacterial cells and purified in complexes with Xenopus H2A or H3, respectively (Perry et al. 1985; Thiriet 2004) (oligonucleotide primer sequences in Supplementary Fig. S1). Flag-tagged dimers and tetramers reconstituted into nucleosomes in vitro in a manner identical to untagged proteins (data not shown). Fluorescently labeled histones were prepared as described (Thiriet and Hayes 2001). Incorporation of exogenous histone complexes were carried out essentially as described (Thiriet and Hayes 2001). Briefly, $400 \mu \mathrm{L}$ of solutions containing $10 \mathrm{mM}$ Tris, $\mathrm{HCl}$ at $\mathrm{pH} 7.2$, $5 \mathrm{mM} \mathrm{ATP}$, and $\sim \mu \mathrm{g} / \mathrm{mL}$ of histone complexes were spread onto the upper surface of macroplasmodia at the desired cell cycle stage for the times noted in the figure legends. Following the incubation, the plasmodia are washed with $5 \mathrm{mM}$ EDTA and then harvested for further analysis (Thiriet and Hayes 1999a; Thiriet 2004).

\section{Confocal analyses}

Following incorporation of fluorescent dimers in G2 phase, macroplasmodium explants were smeared, fixed with ethanol, and permeabilized as described (Thiriet and Hayes 1999a). Cells were stained with antipenta-acetyl H4 tail serum (Upstate Biotechnologies), and rhodaminecoupled goat anti-rabbit secondary antibodies were diluted at $1 / 500$. After exhaustive washings with PBS, the slides were observed with a Leica confocal microscope.

\section{Isolation of nuclei and preparation of chromatin}

Cytosolic extracts and nuclear fractions were prepared by Dounce homogenization as described (Thiriet and Hayes 2001). Nuclei were isolated by percoll gradients as described by Nothacker and Hildebrandt (1988), modified as described (Thiriet 2004). The amount of exogenous proteins in nuclei after incorporation was determined by titrations with standards using anti-Flag Western blots and determination of the total amount of endogenous histones by SDS-PAGE and Coomassie staining against standards. The exogenous histones represent $\sim 5 \%$ of the total histones in the cell in S phase and $\sim 2.5 \%$ in G2 phase. Experiments using $\alpha$-amanitin were carried out according to Pierron and Sauer (1980). Nucleosomes were prepared by MNase digestion of nuclei as described (Thiriet and Hayes 2001), followed by fractionation of $5 \%-20 \%$ sucrose gradients.

\section{ChIP analyses}

Following incubations, macroplasmodia were washed in 5-mM EDTA as described above, then the cells and filter paper support were incubated for $8 \mathrm{~min}$ in $1 \%$ formaldehyde to allow cross-linking. Nuclear fractions were prepared by homogenization, followed by a low-speed centrifugation. Nuclei were sonicated six successive times for $5 \mathrm{sec}$ with output level 2 (Branson sonifier). Chromatin was then separated from the insoluble fraction by centrifugation for $10 \mathrm{~min}$, maximum speed in a standard microfuge $(14 \mathrm{kG})$. Soluble fractions were incubated overnight with antiflag antibody coupled to agarose (Sigma). The beads were then washed as 
recommended by the manufacturer prior to treatment with proteinase $\mathrm{K}$, and cross-links were reversed by heating the samples at $65^{\circ} \mathrm{C}-70^{\circ} \mathrm{C}$ overnight, followed by phenolchloroform extraction and ethanol precipitation (Thiriet 2004). Amplification of immunoprecipitated DNA was carried as described by Hecht and Grunstein (1999) with the primers listed in Supplementary Figure S1. ChIP responses were all normalized to internal controls from unrelated loci and were shown to be in the range of linear response (data not shown).

\section{Acknowledgments}

We thank M. Gorovsky and T. Benyajati for critical comments on the manuscript and J. Waterborg for helpful discussion and sharing of unpublished results. This work was supported by NIH grant GM52426 and NSF grant MCB-0317935.

\section{References}

Ahmad, K. and Henikoff, S. 2002. The histone variant H3.3 marks active chromatin by replication-independent nucleosome assembly. Mol. Cell 9: 1191-1200.

Baer, B.W. and Rhodes, D. 1983. Eukaryotic RNA polymerase II binds to nucleosome cores from transcribed genes. Nature 301: 482-488.

Belotserkovskaya, R., Oh, S., Bondarenko, V.A., Orphanides, G., Studitsky, V.M., and Reinberg, D. 2003. FACT facilitates transcriptiondependent nucleosome alteration. Science 301: 1090-1093.

Benard, M., Lagnel, C., and Pierron, G. 1995. Site-specific initiation of DNA replication within the non-transcribed spacer of Physarum rDNA. Nucleic Acids Res. 23: 1447-1453.

Boeger, H., Griesenbeck, J., Strattan, J.S., and Kornberg, R.D. 2003. Nucleosomes unfold completely at a transcriptionally active promoter. Mol. Cell 11: 1587-1598.

Bradbury, E.M., Inglis, R.J., Matthews, H.R., and Langan, T.A. 1974. Molecular basis of control of mitotic cell division in eukaryotes. Nature 249: 553-556.

Bruno, M., Flaus, A., Stockdale, C., Rencurel, C., Ferreira, H., and OwenHughes, T. 2003. Histone H2A/H2B dimer exchange by ATP-dependent chromatin remodeling activities. Mol. Cell 12: 1599-1606.

Bushnell, D.A., Cramer, P., and Kornberg, R.D. 2002. Structural basis of transcription: $\alpha$-amanitin-RNA polymerase II cocrystal at $2.8 \mathrm{~A}$ resolution. Proc. Natl. Acad. Sci. 99: 1218-1222.

Carrino, J.J. and Laffler, T.G. 1986. Transcription of $\alpha$-tubulin and histone $\mathrm{H} 4$ genes begins at the same point in the Physarum cell cycle. J. Cell. Biol. 102: 1666-1670.

Cosma, M.P. 2002. Ordered recruitment: Gene-specific mechanism of transcription activation. Mol. Cell 10: 227-236.

Hecht, A. and Grunstein, M. 1999. Mapping DNA interaction sites of chromosomal proteins using immunoprecipitation and polymerase chain reaction. Methods Enzymol. 304: 399-414.

Hendzel, M.J. and Davie, J.R. 1990. Nucleosomal histones of transcriptionally active/competent chromatin preferentially exchange with newly synthesized histones in quiescent chicken erythrocytes. Biochem. J. 271: 67-73.

Jackson, V. and Chalkley, R. 1985. Histone synthesis and deposition in the G1 and S phases of hepatoma tissue culture cells. Biochemistry 24: 6921-6930.

Keene, M.A., Corces, V., Lowenhaupt, K., and Elgin, S.C. 1981. DNase I hypersensitive sites in Drosophila chromatin occur at the $5^{\prime}$ ends of regions of transcription. Proc. Natl. Acad. Sci. 78: 143-146.

Kimura, H. and Cook, P.R. 2001. Kinetics of core histones in living human cells: Little exchange of $\mathrm{H} 3$ and $\mathrm{H} 4$ and some rapid exchange of H2B. J. Cell. Biol. 153: 1341-1353.

Kireeva, M.L., Walter, W., Tchernajenko, V., Bondarenko, V., Kashlev, M., and Studitsky, V.M. 2002. Nucleosome remodeling induced by RNA polymerase II: Loss of the $\mathrm{H} 2 \mathrm{~A} / \mathrm{H} 2 \mathrm{~B}$ dimer during transcription. Mol. Cell 9: 541-552.

Lee, C.K., Shibata, Y., Rao, B., Strahl, B.D., and Lieb J.D. 2004. Evidence for nucleosome depletion at active regulatory regions genome-wide. Nat. Genet. 36: 900-905.

Loidl, P. and Grobner, P. 1987. Histone synthesis during the cell cycle of Physarum polycephalum. Synthesis of different histone species is not under a common regulatory control. J. Biol. Chem. 262: 10195-10199.

Lusser, A. and Kadonaga, J.T. 2003. Chromatin remodeling by ATP-de- pendent molecular machines. BioEssays 25: 1192-1200.

Malik, H.S. and Henikoff, S 2003. Phylogenomics of the nucleosome. Nat. Struct. Biol. 10: 882-891.

Maric, C., Benard, M., and Pierron, G. 2003. Developmentally regulated usage of Physarum DNA replication origins. EMBO Rep. 4: 474-478.

McKittrick, E., Gafken, P.R., Ahmad, K., and Henikoff, S. 2004. Histone H3.3 is enriched in covalent modifications associated with active chromatin. Proc. Nat1. Acad. Sci. 101: 1525-1530.

Mello, J.A. and Almouzni, G. 2001. The ins and outs of nucleosome assembly. Curr. Opin. Genet. Dev. 11: 136-141.

Narlikar, G.J., Fan, H.Y., and Kingston, R.E. 2002. Cooperation between complexes that regulate chromatin structure and transcription. Cell 108: $475-487$.

Nothacker, K.D. and Hildebrandt, A. 1988. A method for isolation of nuclei containing undegraded RNA from RNase-rich plasmodia of Physarum polycephalum. Biochim. Biophys. Acta 950: 403-410.

Orphanides, G., Wu, W.H., Lane, W.S., Hampsey, M., and Reinberg, D. 1999. The chromatin-specific transcription elongation factor FACT comprises human SPT16 and SSRP1 proteins. Nature 400: 284-288.

Perry, M., Thomsen, G.H., and Roeder, R.G. 1985. Genomic organization and nucleotide sequence of two distinct histone gene clusters from Xenopus laevis. Identification of novel conserved upstream sequence elements. J. Mol. Biol. 185: 479-499.

Perry, C.A., Dadd, C.A., Allis, C.D., and Annunziato, A.T. 1993. Analysis of nucleosome assembly and histone exchange using antibodies specific for acetylated H4. Biochemistry 32: 13605-13614.

Pierron, G. and Sauer, H.W. 1980. More evidence for replication-transcription-coupling in Physarum polycephalum. J. Cell. Sci. 41: 105113.

Prior, C.P., Cantor, C.R., Johnson, E.M., and Allfrey, V.G. 1980. Incorporation of exogenous pyrene-labeled histone into Physarum chromatin: A system for studying changes in nucleosomes assembled in vivo. Cell 20: 597-608.

Reinke, H. and Horz, W. 2003. Histones are first hyperacetylated and then lose contact with the activated PHO5 promoter. Mol. Cell 11: 1599-1607.

Roth, S.Y., Denu, J.M., and Allis, C.D. 2001. Histone acetyltransferases. Annu. Rev. Biochem. 70: 81-120.

Sathyanarayana, U.G., Freeman, L.A., Lee, M.S., and Garrard, W.T. 1999. RNA polymerase-specific nucleosome disruption by transcription in vivo. J. Biol. Chem. 274: 16431-16436.

Saunders, A., Werner, J., Andrulis, E.D., Nakayama, T., Hirose, S., Reinberg, D., and Lis, J.T. 2003. Tracking FACT and the RNA polymerase II elongation complex through chromatin in vivo. Science 301: 10941096.

Schwabish, M.A. and Struhl, K. 2004. Evidence for eviction and rapid deposition of histones upon transcriptional elongation by RNA polymerase II. Mol. Cell. Biol. 24: 10111-10117.

Thiriet, C. 2004. Analysis of chromatin assembled in vivo using exogenous histones in Physarum polycephalum. Methods 33: 86-92.

Thiriet, C. and Hayes, J.J. 1999a. Chromatin remodeling by cell cycle stage-specific extracts from Physarum polycephalum. Eur. I. Cell. Biol. 78: 214-220.

- 1999b. Histone proteins in vivo: Cell-cycle-dependent physiological effects of exogenous linker histones incorporated into Physarum polycephalum. Methods 17: 140-150.

- 2001. A novel labeling technique reveals a function for histone $\mathrm{H} 2 \mathrm{~A} / \mathrm{H} 2 \mathrm{~B}$ dimer tail domains in chromatin assembly in vivo. Genes \& Dev. 15: 2048-2053.

Waterborg, J.H. and Matthews, H.R. 1983. Intranuclear localization of histone acetylation in Physarum polycephalum and the structure of functionally active chromatin. Cell Biophys. 5: 265-279.

Wolffe, A.P. 1998. Chromatin structure and function. Academic Press, San Diego, CA.

Wu, C. 1980. The 5' ends of Drosophila heat shock genes in chromatin are hypersensitive to DNase I. Nature 286: 854-860.

Wu, C., Wong, Y.C., and Elgin, S.C. 1979. The chromatin structure of specific genes: II. Disruption of chromatin structure during gene activity. Cell 16: 807-814.

Zhang, Y. and Reinberg, D. 2001. Transcription regulation by histone methylation: Interplay between different covalent modifications of the core histone tails. Genes \& Dev. 15: 2343-2360. 


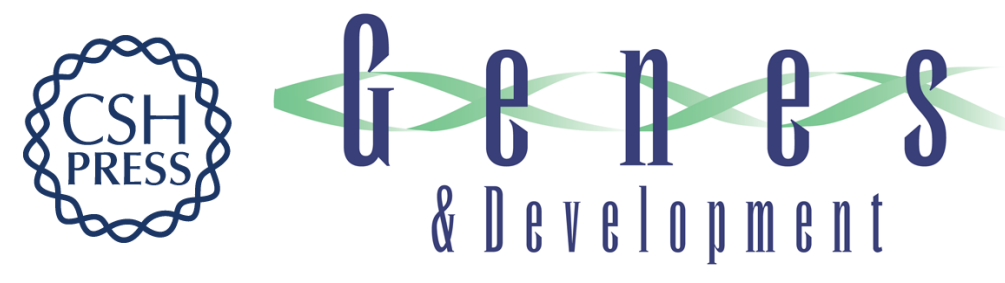

\section{Replication-independent core histone dynamics at transcriptionally active loci in vivo}

Christophe Thiriet and Jeffrey J. Hayes

Genes Dev. 2005, 19:

Access the most recent version at doi:10.1101/gad.1265205

\section{Supplemental http://genesdev.cshlp.org/content/suppl/2005/03/02/19.6.677.DC1 Material}

References This article cites 43 articles, 14 of which can be accessed free at: http://genesdev.cshlp.org/content/19/6/677.full.html\#ref-list-1

\section{License}

Email Alerting

Receive free email alerts when new articles cite this article - sign up in the box at the top Service

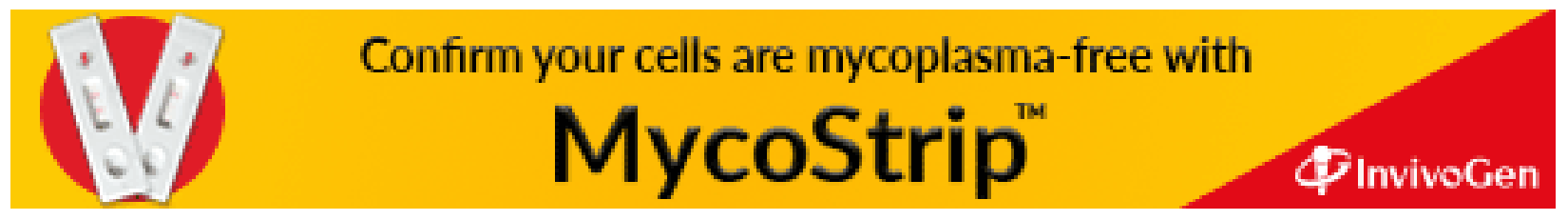

